\section{Association between treatment adherence and quality of life among overweight adolescents}

\section{Associação entre adesão terapêutica e qualidade de vida em adolescentes com sobrepeso}

\section{Asociación entre adhesión terapéutica y calidad de vida en adolescentes con sobrepeso}

Pedro Miguel Lopes de Sousa 1

Pedro Gaspar 1

Helena Fonseca 2

Filomena Gaspar 3

\begin{abstract}
Overweight is an extra burden for adolescent development and can trigger severe physical and psychosocial problems. This cross-sectional correlational study aimed to analyze the association between treatment adherence and obesity-related quality of life among overweight adolescents. The sample consisted of 94 adolescents attending a specialized Pediatric Obesity Clinic in Portugal, $48.94 \%$ of whom were boys and $51.06 \%$ girls, with a median age of 14.17 years $(S D=1.51)$. A positive correlation was found between obesity-related quality of life and adherence to weight control. The influence of parents and caregivers on the adherence to weight control is significantly associated with increased physical comfort, better social life and family relations. These results highlight the importance of behavioral change and adherence to weight control as pillars of a better quality of life among overweight adolescents. Obesity management programs need to focus on multiple criteria of treatment effectiveness, such as obesity-related quality of life.
\end{abstract}

Overweight; Quality of Life; Patient Compliance; Adolescent

\author{
Correspondence \\ P. M. L. Sousa \\ Unidade de Investigação em Saúde, Instituto Politécnico de \\ Leiria. \\ Rua General Norton de Matos, Apartado 4133, Leiria \\ 2411-901, Portugal. \\ pedro.sousa@ipleiria.pt \\ 1 Unidade de Investigação em Saúde, Instituto Politécnico de \\ Leiria, Leiria, Portugal. \\ 2 Faculdade de Medicina, Universidade de Lisboa, Lisboa, \\ Portugal. \\ ${ }_{3}^{3}$ Escola Superior de Enfermagem de Lisboa, Lisboa, Portugal.
}




\section{Introduction}

According to the World Health Organization (WHO), 170 million children (aged under 18) are now estimated to be overweight. Obesity is currently the fifth leading risk factor for early mortality and is responsible for $7-41 \%$ of malignant disease cases, $44 \%$ of diabetes and $23 \%$ of ischemic heart disease cases ${ }^{1}$. The condition, which is considered by the WHO to be the primary cause of global preventable diseases, leads to a significant decrease in life expectancy, particularly due to the vast number of associated comorbidities 2,3. Portugal has the sixth highest obesity rate among European countries 4.

Adolescence is a stage of life characterized by dramatic changes in the process of growth and development. Obesity may add an extra burden to this already complex process 5 . It is essential to invest in effective treatment of overweight adolescents 6 , because adolescent obesity: (a) has a significant impact on physical and psychosocial health, (b) is an important risk factor for early morbidity and mortality in adulthood, and (c) is a major threat to the sustained increase in life expectancy 7.

Obese adolescents often present a lower quality of life in the physical, psychosocial, emotional, and school functioning domains, when compared to non-obese adolescents of a similar age 2,5,8. Moreover, the psychosocial morbidities are usually underestimated by both parents and health professionals, despite their negative impact on adolescent development 7 . Overweight adolescents often suffer from social rejection, feel discriminated and stigmatized at school, have a poor self-image and are at increased risk of developing low self-esteem and depression 9,10.

Treating overweight patients implies adherence to behavioral changes $11,12,13,14$. There is little data on adherence rates to weight loss in interventions targeting adolescents and on their measurement and evaluation ${ }^{15}$. It is estimated that there is a $50 \%$ treatment dropout rate among obese adolescents, and that less than $5 \%$ are able to maintain the weight loss after five years 15 .

The success of any intervention in this field lays in the control of individual needs and promotion of adherence to weight control treatment and behavioral change strategies 13,16. There is evidence that treatment adherence is critical for effective weight control management. Therefore, focusing on adherence can be the best investment for success 17,18 .

Treatment adherence is defined by WHO 18 as the extent to which a person's behavior (e.g. taking medication, following a diet, and/or executing lifestyle changes) corresponds with agreed recommendations from a health care provider. A better understanding of the phenomenon of therapeutic adherence in children tailored to family needs may facilitate health care delivery 19.

The success of a weight management intervention may depend on understanding the needs of overweight adolescents and how much and in which ways their health-related quality of life (HRQOL) is impaired 20. Some of the HRQOL predictors were already identified, such as gender, depressive symptoms, classroom social support, age and socioeconomic status 21.

To our knowledge, this is the first study that analyzes the association between treatment adherence and quality of life among overweight adolescents. The main objective of this research was to investigate the association between adherence to weight control and HRQOL among overweight adolescents. It was hypothesized that a higher adherence to weight control was associated with better HRQOL.

\section{Methods}

\section{Study design and participants}

This study is based on Pender's Health Promotion Model 11. In this study we measure the core components of the model, namely the "individual characteristics and experiences" (e.g. anthropometric and sociodemographic variables), the "behavior-specific cognitions and affect" (e.g. self-efficacy and adherence behaviors; parental and provider influence; friends and school influence and perceived benefits). Pender's model represents a multidimensional view of health promotion behaviors 12 , and considers that the greater the commitments to a specific plan of action, the more likely healthpromoting behaviors are to be maintained over time. Health promoting behaviors should result in improved health, enhanced functional ability and better quality of life at all stages of development 12 . 
This cross-sectional correlational study was conducted based on a secondary analysis of a previous data set. Data were obtained from the first wave of an ongoing controlled trial 22 of an Internetbased adolescent obesity intervention programme. Participants $(N=94)$ are adolescents treated at the Pediatric Obesity Clinic of the Santa Maria Hospital (a tertiary referral hospital in Portugal), aged between 12 and 18 years, fulfilling the U.S. Centers for Disease Control and Prevention (CDC) criteria for overweight (body mass index - BMI percentile $\geq 85$ th). Exclusion criteria were the presence of severe psychopathology, inability to communicate in writing, pregnancy and having been proposed for bariatric surgery. These adolescents were already following the standard clinical program, which includes a baseline evaluation session with a pediatrician, nutritionist and exercise physiologist for initial screening, with follow-up appointments every 3 to 4 months. Sample recruitment had the support of the clinical staff. All eligible adolescents with appointments between January 1st and December 31 st 2012 were invited to participate $(\mathrm{n}=140)$.

\section{Measures}

Data were obtained from the first wave of an ongoing controlled trial (baseline evaluation) 22. Data were collected from different sources: clinical files (demographic, anthropometric, behavioral variables); and self-report instruments (Adherence to Weight Control Questionnaire - AWCQ, Impact of Weight on Quality of Life - IWQOL). We also calculated the time elapsed since the first visit until the recruitment date to this study (in months).

\section{- Demographic variables}

The information regarding the adolescent demographic variables was collected from the clinical file (information obtained by the clinical staff), including age, gender, parental profession and parental education. Information on parental profession were collected according to the Portuguese Classification of Occupations and later grouped according to the differentiation degree, into class 1 (managers and professionals), class 2 (technicians and associate professionals; clerical support workers; service and sales workers) and class 3 (skilled agricultural, forestry and fishery workers; craft and related trades workers; plant and machine operators, and assemblers; elementary occupations). The higher the class, the higher the differentiation. Information on parental education were grouped into "none", "first cycle" (1st to $4^{\text {th }}$ year), "second cycle" (5th and 6 th year), "third cycle" (7th to 9th year), "secondary education" (10th to $12^{\text {th }}$ year) and "higher education" (university education and polytechnic education). In this study we consider the differentiation degree of parental occupation and the parental education as proxy indicators of socioeconomic status 23 .

\section{- Anthropometric variables}

Anthropometric indicators (BMI percentile, BMI z-score and waist circumference percentile) and measures (hip circumference) were obtained by trained health professionals at the clinic, based on the International Standards for Anthropometric Assessment 24. BMI cut-offs endorsed by the CDC 25 were used.

\section{- Behavioral variables}

The information regarding the behavioral variables was collected from the clinical file (information obtained by clinical staff).

Weekly physical activity was measured by asking adolescents how many hours they spent doing structured physical activity in a typical week (hours/week) 22. The concept of structured physical activity was explained during the clinical interview.

Screen time was obtained by asking adolescents the average number of leisure-time hours they spent playing video games and watching television, DVDs or videos, for both weekdays and weekend days (hours/week) 22. 
This was an instrument developed and validated by Sousa et al. 26. This screening tool measures "Treatment Adherence to Weight Control" (TAWC) and the "Risk of Non-Adherence to Weight Control" (RNAWC) in adolescents, with a five-point Likert-type format. The TAWC scale was designed to evaluate the adherence behaviors/strategies as well as the intention/expectation of adherence, including the perception of benefits, interpersonal influences and self-efficacy. The RNAWC scale was designed to evaluate the perception of barriers to adherence. The TAWC (29 items) includes four subscales: SEA (Self-Efficacy and Adherence Behaviors), PPI (Parental and Provider Influence), FSI (Friends and School Influence) and PB (Perceived Benefits). The RNAWC (7 items) presented a one-factor solution. Both scales presented good reliability values (0.908 and 0.770 ) and a five-point Likert-type format. A high TAWC score corresponds to a greater treatment adherence. Furthermore, a high RNAWC score corresponds to a greater risk of non-adherence. Results may vary from 1 to 5 .

\section{- IWQOL}

This questionnaire consists of 27 items organized into four factors (physical comfort, body esteem, social life and family relations). The original questionnaire is the IWQOL-Kids from Kolotkin et al. 27 that was translated to Portuguese and validated by Palmeira et al. 28 with 522 adolescents, presenting internal consistency values between 0.75-0.93 (0.934 for the total scale). For the purpose of this study we used the Portuguese version. A high IWQOL score corresponds to a better obesity-related quality of life. Results may vary from 1 to 100 .

\section{Data analysis}

Descriptive statistics, including measures of frequency, central tendency, and distribution were used to describe the sample characteristics and study variables. All analyses were carried out using bilateral tests and alphas of 0.05. Nonparametric tests were used in inferential statistics, due to a non-normal distribution of the data. Spearman correlations were used to assess the associations between the variables and test the hypothesis. All analyses were conducted using version 18 of the SPSS software (SPSS Inc., Chicago, U.S.A.).

\section{Procedures}

This study was approved in January 2012 by the Ethics Committee for Health (Lisbon, Portugal) and funded by the Foundation for Science and Technology (PTDC/DTP-PIC/0769/2012). All eligible adolescents and respective parents that agreed to participate in this study signed an informed consent form where the study objectives were explained, in accordance with the Declaration of Helsinki and the ethical principles of the American Psychological Association. Confidentiality and voluntary participation were assured.

\section{Results}

The sample consisted of 94 adolescents who are attending a specialized Pediatric Obesity Clinic, in Portugal, $48.94 \%$ of whom were boys and $51.06 \%$ girls, with a median age of 14.17 years (SD $=1.51$ ). The descriptive results of the variables are described in Table 1. The mean BMI z-score was $2.065(\mathrm{SD}=$ 0.377), corresponding to a mean BMI percentile of 97.362 ( $\mathrm{SD}=2.193$ ). Parents with a higher education were a minority (6.4\% of fathers; $10 \%$ of mothers) and many parents work in "services and sales" ( $25.6 \%$ of fathers; $28.2 \%$ of mothers).The high percentage of unemployed parents is of note $(11.5 \%$ of fathers; $9 \%$ of mothers). Statistically significant differences between genders were only found for screen time $(\mathrm{U}=157.000, \mathrm{p}=0.033)$, with boys spending more time in front of screens $(24.820 \pm$ 11.709 vs. $17.625 \pm 10.454)$. 
Table 1

Characteristics of the participants by age, previous treatment length, adherence to weight control, obesity-related quality of life, anthropometric and behavioral variables.

\begin{tabular}{|c|c|c|c|c|c|c|}
\hline \multirow[t]{2}{*}{ Variables } & \multicolumn{2}{|c|}{ Boys $(n=46)$} & \multicolumn{2}{|c|}{ Girls $(n=48)$} & \multicolumn{2}{|c|}{ Total $(\mathrm{N}=94)$} \\
\hline & M & SD & M & SD & M & SD \\
\hline Age & 14.457 & 1.441 & 13.896 & 1.533 & 14.170 & 1.507 \\
\hline \multicolumn{7}{|l|}{ Anthropometric variables } \\
\hline BMI z-score & 2.157 & 0.360 & 1.989 & 0.364 & 2.065 & 0.377 \\
\hline BMI percentile & 95.692 & 14.643 & 96.980 & 2.177 & 97.362 & 2.193 \\
\hline Waist circumference percentile & 92.000 & 3.114 & 91.848 & 3.337 & 91.797 & 3.368 \\
\hline Hip circumference $(\mathrm{cm})$ & 109.26 & 10.24 & 109.43 & 11.86 & 109.10 & 10.67 \\
\hline \multicolumn{7}{|l|}{ Behavioral variables } \\
\hline Weekly physical activity (hours/week) & 5.28 & 4.41 & 3.60 & 2.41 & 4.50 & 3.69 \\
\hline Screen time (hours/week) & 24.82 & 11.71 & 17.63 & 10.45 & 21.62 & 11.62 \\
\hline Previous treatment length (months) & 26.21 & 28.54 & 19.88 & 23.60 & 23.08 & 26.25 \\
\hline \multicolumn{7}{|l|}{ Adherence to weight control * } \\
\hline Self-efficacy/Adherence behaviors & 3.266 & 0.866 & 3.197 & 0.807 & 3.230 & 0.832 \\
\hline Parental and provider influence & 4.450 & 0.481 & 4.494 & 0.683 & 4.473 & 0.590 \\
\hline Friends and school influence & 3.415 & 0.844 & 3.542 & 0.777 & 3.480 & 0.808 \\
\hline Perceived benefits & 4.230 & 0.775 & 4.241 & 0.975 & 4.236 & 0.878 \\
\hline TAWC total score & 3.724 & 0.578 & 3.736 & 0.581 & 3.730 & 0.576 \\
\hline Risk of non-adherence & 2.676 & 0.955 & 2.344 & 0.741 & 2.506 & 0.864 \\
\hline \multicolumn{7}{|l|}{ Obesity-related quality of life ** } \\
\hline Physical comfort & 79.601 & 24.083 & 85.319 & 17.165 & 82.491 & 20.959 \\
\hline Body esteem & 71.732 & 27.117 & 61.096 & 28.206 & 66.357 & 28.036 \\
\hline Social life & 83.514 & 22.012 & 82.801 & 22.246 & 83.154 & 22.013 \\
\hline Family relations & 92.844 & 17.714 & 94.770 & 15.060 & 93.817 & 16.365 \\
\hline IWQOL total score & 80.789 & 20.266 & 78.823 & 17.780 & 79.795 & 18.972 \\
\hline
\end{tabular}

IWQOL: Impact of Weight on Quality of Life; M: median; TAWC: Treatment Adherence to Weight Control;

SD: standard deviation.

* Scale range: 1-5;

** Scale range: $1-100$.

Regarding weight control adherence (scale range: 1-5), the overall risk of a non-adherence score was $2.506 \pm 0.864$, while for the overall treatment adherence score, the value rose to $3.730 \pm 0.576$. Of note are the high levels of PB and PPI.

The obesity-related quality of life score (scale range: 1 -100) was 79.795 (SD =18.972). Among the subscales, the higher values were found in "family relations" $(93.817 \pm 16.365)$ and the lowest values in "body esteem" (66.357 \pm 28.036$)$.

\section{Association between treatment adherence and obesity-related quality of life}

The analysis of the correlation between treatment adherence and IWQOL (Table 2) revealed that the larger the self-efficacy/adherence behavior index, the higher the body esteem $\left(\mathrm{r}_{\mathrm{s}}=0.282, \mathrm{p}<0.01\right)$ and the obesity-related quality of life index $\left(\mathrm{r}_{\mathrm{s}}=0.275, \mathrm{p}<0.01\right)$.

The influence of parents and health professionals on the adherence to weight control is associated to an increased rating of physical comfort $\left(r_{s}=0.253, p<0.05\right)$, social life $\left(r_{s}=0.237, p<0.05\right)$, family relations $\left(\mathrm{r}_{\mathrm{s}}=0.326, \mathrm{p}<0.01\right)$ and obesity-related quality of life index $\left(\mathrm{r}_{\mathrm{s}}=0.236, \mathrm{p}<0.05\right)$.

Finally, results indicate that overall higher indices of adherence to weight control are associated to several higher indices of IWQOL (coefficients between 0.225 and $0.289, \mathrm{p}<0.05$ ). 
Table 2

Spearman correlations between obesity-related quality of life and adherence to weight control.

\begin{tabular}{lccccc}
\hline Variables & PC & BE & SL & FR & $\begin{array}{c}\text { IWQOL total } \\
\text { score }\end{array}$ \\
\hline Adherence to weight control & & & & & \\
Self-efficacy/Adherence behaviors & 0.165 & $0.282 *$ & 0.175 & 0.112 & $0.275 *$ \\
Parental and provider influence & $0.253 * *$ & 0.148 & $0.237 * *$ & $0.326 *$ & $0.236 * *$ \\
Friends and school influence & 0.116 & 0.120 & 0.149 & 0.162 & 0.154 \\
Perceived benefits & 0.070 & -0.176 & -0.006 & -0.022 & -0.118 \\
TAWC total score & $0.225 * *$ & $0.246 * *$ & $0.251 * *$ & 0.198 & $0.289 *$ \\
Risk of non-adherence & -0.099 & -0.145 & -0.108 & -0.070 & -0.154 \\
\hline
\end{tabular}

BE: body esteem; FR: family relations; IWQOL: Impact of Weight on Quality of Life; PC: physical comfort; SL: social life; TAWC: Treatment Adherence to Weight Control.

* $p$-value $<0.01$;

** -value $<0.05$.

The risk of non-adherence does not significantly influence treatment adherence or obesityrelated quality of life scores ( $\mathrm{p}>0.05$ ).

Regarding the fact that these adolescents were already following the standard clinical program, the influence of the previous treatment length on treatment adherence and obesity-related quality of life was further analyzed. Results indicate that the time elapsed since the first appointment does not significantly influence treatment adherence or obesity-related quality of life scores $(p>0.05)$.

\section{Discussion}

With its focus on weight control treatment, this study analyzed the influence of treatment adherence on obesity-related quality of life. It has long been understood that treatment adherence is essential for successful weight control 11,12,13,14.

In this research, the "adherence to weight control" domains that scored higher were benefit perception and recognition of parental/provider influence. The risk of nonadherence was moderated, highlighting the fact that overweight adolescents experience several barriers to participation in behavioral change interventions. The problem of non-adherence remains a challenge for both health professionals and researchers and is responsible for a significant number of people not getting the maximum benefit from treatment, leading to poor health outcomes, reduced quality of life and increased health care costs 29 .

Noteworthy is the significant correlation between obesity related quality of life and adherence to weight control. A closer look showed that the influence of parents and caregivers is significantly associated with increased physical comfort, better social life and family relations. Several authors recognize that regular contact with health professionals during the behavioral change process is likely to improve therapeutic adherence 30,31,32, and that parental involvement and adolescents' motivation are the key for a successful adherence to behavioral change 33 .

These results highlight the importance of keeping adolescents motivated throughout the whole weight management process. Along the same lines, the U.S. National Institute of Health stressed the importance of motivating for weight loss as a key factor in assessing whether the individual is prepared to start treatment and to adjust to the necessary lifestyle changes 31 .

These results highlight the importance of behavioral change and adherence to weight control as pillars of a better quality of life among overweight adolescents. Obesity management programs need to focus on multiple criteria of treatment effectiveness, such as obesity-related quality of life. 
A number of strengths and limitations should be borne in mind when considering the results reported here. The main strength of this research is its use of obesity specific instruments, that are typically more sensitive than generic instruments to changes in quality of life that result from treatment 21 , making it possible to reduce the confounding influence of medical comorbidities.

Study limitations include the non-randomized nature of the study, differential exposure to weight loss treatment and the limited amplitude range of BMI percentiles, limiting a full exploration of differences in psychosocial variables. Future research should use a larger randomized sample, with a larger BMI variance, as well as use complementary techniques of multivariate analysis.

\section{Conclusions}

These results underscore the importance of routinely assessing quality of life when treating overweight adolescents due to a positive correlation between obesity-related quality of life and adherence to weight control. Promoting the influence of parents and caregivers may lead to increased physical comfort, and better social lives and family relations.

It is likely that assessing and fostering adherence to weight control in the context of pediatric interventions have implications for both improved IWQOL and weight management outcomes.

Tailored obesity management programs need to focus not only on controlling BMI, but also on other important treatment effectiveness outcomes, such as obesity-related quality of life.

\section{Contributors}

P. M. L. Sousa and P. Gaspar participated in the conception of the study design, data analysis, interpretation of the results, writing and final approval of the article. H. Fonseca contributed in the conception of the study design, writing and final approval of the article. F. Gaspar contributed towards the critical review of the article and final approval of the article.

\section{Acknowledgments}

We gratefully acknowledge the clinical staff of the Pediatric Obesity Clinic for their dedication. We also thank all the adolescents and parents for their participation and collaboration. Our thanks also to the Foundation for Science and Technology (PTDC/ DTP-PIC/0769/2012) for their financial support.

\section{References}

1. World Health Organization. Population-based prevention strategies for childhood obesity. Geneva: World Health Organization; 2010.

2. Branca F, Nikogosian H, Lobstein T. The challenge of obesity in the WHO European Region and the strategies for response. Geneva: World Health Organization; 2007.

3. Steele R, Nelson T, Jelalian E. Pediatric obesity: trends and epidemiology. In: Jelalian E, Steele R, editors. Handbook of childhood and adolescent obesity. New York: Springer; 2008. p. 3-10.

4. Costa C, Ferreira M, Amaral R. Obesidade infantil e juvenil. Acta Med Port 2010; 23:379-84.

5. Fonseca H. Obesidade na adolescência: um contributo para a melhor compreensão dos factores psicossociais associados à obesidade e excesso de peso nos adolescentes portugueses [Doctoral Dissertation]. Lisboa: Faculdade de Medicina, Universidade de Lisboa; 2008.

6. Oude Luttikhuis H, Baur L, Jansen H, Shrewsbury V, O'Malley C, Stolk R, et al. Interventions for treating obesity in children. Cochrane Database Syst Rev 2009; (1):CD001872.

7. Singh A, Mulder C, Twisk J, van Mechelen W, Chinapaw M. Tracking of childhood overweight into adulthood: a systematic review of the literature. Obes Rev 2008; 9:474-88. 
8. Schwimmer J, Burwinkle T, Varni J. Health-related quality of life of severely obese children and adolescents. JAMA 2003; 289:1813-9.

9. Association of State and Territorial Health Officials. Childhood obesity: harnessing the power of public and private partnerships. Washington DC: National Institute for Health Care Management Foundation; 2007.

10. Ferriani M, Dias T, Silva K, Martins C. Auto-imagem corporal de adolescentes atendidos em um programa multidisciplinar de assistência ao adolescente obeso. Rev Bras Saúde Matern Infant 2005; 5:27-33.

11. Hendricks C, Murdaugh C, Pender N. The adolescent lifestyle profile: development and psychometric characteristics. J Natl Black Nurses Assoc 2006; 17:1-5.

12. Pender N, Murdaugh C, Parsons M. Health promotion in nursing practice. $6^{\text {th }}$ Ed. Upper Saddle River: Pearson/Prentice-Hall; 2010.

13. Elfhag K, Rossner S. Who succeeds in maintaining weight loss? A conceptual review of factors associated with weight loss maintenance and weight regain. Obes Rev 2005; 6:67-85.

14. Walpole B, Dettmer E, Morrongiello B, McCrindle $B$, Hamilton J. Motivational Interviewing as an intervention to increase adolescent self-efficacy and promote weight loss: methodology and design. BMC Public Health 2011; 11:459.

15. França S, Sahade V, Nunes M, Adan L. Adherence to nutritional therapy in obese adolescents: a review. Nutr Hosp 2013; 28:988-98.

16. Brown T, Avenell A, Edmunds L, Moore H, Whittaker V, Avery L, et al. Systematic review of longterm lifestyle interventions to prevent weight gain and morbidity in adults. Obes Rev 2009; 10: 627-38.

17. Davin S, Taylor N. Comprehensive review of obesity and psychological considerations for treatment. Psychol Health Med 2009; 14:716-25.

18. World Health Organization. Adherence to longterm therapies: evidence for action. Geneva: World Health Organization; 2003.

19. Chisholm V, Atkinson L, Donaldson C, Noyes K, Payne A, Kelnar C. Predictors of treatment adherence in young children with type 1 diabetes. J Adv Nurs 2007; 57:482-93.

20. Stubbs J, Whybrow S, Teixeira P, Blundell J, Lawton C, Westenhoefer J. Problems in identifying predictors and correlates of weight loss and maintenance: implications for weight control therapies based on behaviour change. Obes Rev 2011; 12:688-708.

21. Zeller M, Modi A. Psychosocial factors related to obesity in children and adolescents. In: Jelalian E, Steele, R, editors. Handbook of childhood and adolescent obesity. New York: Springer; 2008. p. 25-42.
22. Sousa P, Fonseca H, Gaspar P, Gaspar F. Internetbased intervention programme for obese adolescents and their families (Next.Step): research protocol of a controlled trial. J Adv Nurs 2014; 70:904-14.

23. Fujishiro K, Xu J, Gong F. What does "occupation" represent as an indicator of socioeconomic status? Exploring occupational prestige and health. Soc Sci Med 2010; 71:2100-7.

24. Stewart A, Marfell-Jones M, Olds T, de Ridder H. International standards for anthropometric assessment. Underdale: International Society for the Advancement of Kinanthropometry; 2011.

25. Kuczmarski R, Ogden C, Grummer-Strawn L, Flegal KM, Guo SS, Wei R, et al. CDC growth charts: United States. Adv Data 2000; (314):1-27.

26. Sousa P, Fonseca H, Gaspar P. Measuring adherence to weight control in adolescents: development and validation of a self-report questionnaire. Aten Primaria (Barc., Ed. impr.) 2013; 45(Suppl I): 70-1.

27. Kolotkin R, Zeller M, Modi A, Samsa G, Quinlan N, Yanovski J, et al. Assessing weight-related quality of life in adolescents. Obesity (Silver Spring) 2006; 14:448-57.

28. Palmeira A, Martins S, Costa R, Quaresma A, Fonseca $\mathrm{H}$, Teixeira $\mathrm{P}$, et al. Confirmatory factor analysis of the Portuguese version of the Impact of Weight on Quality of Life-Kids. Obesity (Silver Spring) 2008; 16 Suppl 1:S112.

29. Dulmen S, Sluijs E, Dijk L, Ridder D, Heerdink R, Bensing J. Patient adherence to medical treatment: a review of reviews. BMC Health Serv Res 2007; 7:13.

30. Baulch J, Chester A, Brennan L. Treatment alternatives for overweight and obesity: the role of online interventions. Behav Change 2008; 25:1-14.

31. National Institutes of Health. The practical guide: identification, evaluation, and treatment for overweight and obesity in adults. Bethesda: National Institutes of Health; 2000.

32. Shaw K, O'Rourke P, Del Mar C, Kernardy J. Psychological interventions for overweight and obesity (review). Cochrane Database Syst Rev 2005; (2):CD003818.

33. Naar-King S, Jen K. Interventionist procedures for adherence to weight loss recommendations in black adolescents. http://clinicaltrials.gov/ct2/ show/NCT01350531 (accessed on 25/Jan/2013). 


\section{Resumo}

O sobrepeso representa um ônus adicional para o desenvolvimento do adolescente e pode provocar problemas físicos de psicossociais. Este estudo correlacional transversal teve como objetivo analisar a associação entre adesão terapêutica e qualidade de vida associada à obesidade entre adolescentes com sobrepeso. A amostra consistia em 94 adolescentes que frequentavam uma clínica pediátrica especializada em obesidade em Portugal (48,94\% meninos; 51,06\% meninas), com mediana de idade de 14,17 anos ( $D P=1,51)$. Foi demonstrada uma correlação positiva entre qualidade de vida relacionada à obesidade e adesão ao controle de peso. $O$ estudo mostra uma associação positiva entre a influência dos pais e cuidadores sobre a adesão ao controle de peso e o aumento do conforto físico e a vida social e relações familiares. Os resultados destacam a importância de mudanças comportamentais e adesão ao controle de peso como pilares para uma melhor qualidade de vida entre adolescentes com sobrepeso. Os programas para o manejo da obesidade devem priorizar múltiplos critérios de efetividade terapêutica, tais como qualidade de vida relacionada à obesidade.

Sobrepeso; Qualidade de Vida; Cooperação do Paciente; Adolescente

\section{Resumen}

El sobrepeso representa una carga adicional para el desarrollo del adolescente y puede provocar problemas físicos y psicosociales. Este estudio correlacional transversal tuvo como objetivo analizar la asociación entre adhesión terapéutica y calidad de vida, asociada a la obesidad entre adolescentes con sobrepeso. La muestra consistía en 94 adolescentes que frecuentaban una clínica pediátrica, especializada en obesidad en Portugal (48,94\% niños; 51,06\% niñas), con una media de edad de 14,17 años $(D P=1,51)$. Se demostró una correlación positiva entre calidad de vida relacionada con la obesidad y adhesión al control de peso. El estudio muestra una asociación positiva entre la influencia de los padres y cuidadores sobre la adhesión al control de peso y el aumento de confort físico, la vida social y relaciones familiares. Los resultados destacan la importancia de cambios comportamentales y de adhesión al control de peso como pilares para una mejor calidad de vida entre adolescentes con sobrepeso. Los programas para el manejo de la obesidad deben priorizar múltiples criterios de efectividad terapéutica, tales como calidad de vida relacionada con la obesidad.

Sobrepeso; Calidad de Vida; Cooperación del Paciente; Adolescente
Submitted on $18 /$ Oct $/ 2015$

Final version resubmitted on 08/Mar/2016

Approved on 06/Apr/2016 